\title{
Clinicopathological Features and Treatment of Ectopic Varices with Portal Hypertension
}

\author{
Takahiro Sato, Jun Akaike, Jouji Toyota, Yoshiyasu Karino, and Takumi Ohmura \\ Department of Gastroenterology, Sapporo Kosei General Hospital, Kita 3 Higashi 8, Chuo-ku, Sapporo 060-0033, Japan \\ Correspondence should be addressed to Takahiro Sato, taka.sato@ja-hokkaidoukouseiren.or.jp
}

Received 15 January 2011; Accepted 12 May 2011

Academic Editor: Deepak Amarapurkar

Copyright () 2011 Takahiro Sato et al. This is an open access article distributed under the Creative Commons Attribution License, which permits unrestricted use, distribution, and reproduction in any medium, provided the original work is properly cited.

Bleeding from ectopic varices, which is rare in patients with portal hypertension, is generally massive and life-threatening. Fortythree patients were hospitalized in our ward for gastrointestinal bleeding from ectopic varices. The frequency of ectopic varices was 43/1218 (3.5\%) among portal hypertensive patients in our ward. The locations of the ectopic varices were rectal in thirty-two, duodenal in three, intestinal in two, vesical in three, stomal in one, and colonic in two patients. Endoscopic or interventional radiologic treatment was performed successfully for ectopic varices. Hemorrhage from ectopic varices should be kept in mind in patients with portal hypertension presenting with lower gastrointestinal bleeding.

\section{Introduction}

Portal hypertension can result in either the reopening of collapsed embryonic channels or reversal of the flow within existing adult veins [1]. Whilst esophagogastric varices are the most common complication in patients with portal hypertension, ectopic varices defined by large portosystemic venous collaterals occurring anywhere in the gastrointestinal tract, other than the esophagogastric region, are less common and account for between $1 \%$ and $5 \%$ of all variceal bleeding $[2,3]$. Ectopic varices that are not esophagogastric are located predominantly in the duodenum, jejunum, ileum, colon, rectum, and enterostomy stoma. Bleeding from ectopic varices, which is rare in patients with portal hypertension, is generally massive and life-threatening. However, there are few reports on the clinicopathological features of ectopic varices. Endoscopic injection sclerotherapy (EIS) is now a standard procedure for the treatment of esophageal varices [4] and, recently, endoscopic band ligation (EBL) has been used widely to treat esophageal varices [5]. Balloonoccluded retrograde transvenous obliteration (B-RTO) is a new interventional modality for gastric fundic varices [6]. However, a definitive treatment has not been established for bleeding ectopic varices.

In this paper, we evaluate the clinicopathological features and treatment of ectopic varices in our ward.

\section{Clinicopathological Features of Ectopic Varices}

Esophagogastric varices are considered to be the most common complication in patients with portal hypertension, while ectopic varices (i.e., those outside the esophago-gastric region) are less common. Ectopic varices have been reported to occur at numerous sites, including $18 \%$ in the jejunum or ileum, $17 \%$ in the duodenum, $14 \%$ in the colon, $8 \%$ in the rectum, and $9 \%$ in the peritoneum [7].

From January 1994 to March 2009, we performed endoscopic or interventional radiologic treatment for 1218 portal hypertensive patients with esophagogastric varices. During this period, 43 patients were hospitalized in our ward for gastrointestinal bleeding from ectopic varices. There were 21 males and 22 females, ranging in age from 38 to 84 years (mean, 67.0 years). The underlying pathology of portal hypertension included liver cirrhosis (LC) in 22 patients, cirrhosis associated with hepatocellular carcinoma (HCC) in 9, primary biliary cirrhosis (PBC) in 3, idiopathic portal hypertension (IPH) in 6, extrahepatic portal vein obstruction (EHO) in 2, and another disease in 1 (Table 1). In terms of the clinical staging of cirrhosis, 22 patients were graded Child-Pugh class A, 18 class B, and 3 class C. The etiologies of LC were hepatitis B surface antigen ( $\mathrm{HBsAg}$ ) positivity in 4 patients, antibody to hepatitis $\mathrm{C}$ virus (anti-HCV) in 
TABLE 1: Underlying pathologies in patients with ectopic varices.

\begin{tabular}{lc}
\hline & Cases $(N)$ \\
\hline Liver cirrhosis & 22 \\
Cirrhosis associated hepatocellular carcinoma & 9 \\
Idiopathic portal hypertension & 6 \\
Primary biliary cirrhosis & 3 \\
Extrahepatic portal vein obstruction & 2 \\
Other & 1 \\
\hline Total & 43 \\
\hline
\end{tabular}

16 patients, alcoholic liver disease in 8 patients, sarcoidosis in 1 patient, and unknown in 2 patients.

The frequency of ectopic varices was 43/1218 (3.5\%) among portal hypertensive patients in our ward. The locations of the ectopic varices were rectal in 32 , duodenal in 3 , small intestinal in 2, vesical in 3, stomal in 1 , and colonic in 2 patients (Table 2). Thirty-nine of 43 patients with ectopic varices had previously received emergency or prophylactic EIS for esophageal varices. Nine patients had a history of esophageal variceal bleeding, and emergency EIS had been performed in these cases. Prophylactic EIS had been performed on 30 patients with esophageal varices because of a high risk of bleeding.

\section{Rectal Varices}

Thirty two rectal variceal patients in our ward had had undergone EIS or EBL. There were 14 males and 18 females, ranging in age from 38 to 84 years (mean, 67.0 years). The underlying pathology causing portal hypertension included LC in 16 patients, cirrhosis associated with HCC in 7 patients, IPH in 4 patients, $\mathrm{PBC}$ in 3 patients, and $\mathrm{EHO}$ in 2 patients. In terms of the clinical staging of cirrhosis, 15 patients were graded Child-Pugh class A, 15 class B, and 2 class C. The etiologies of LC were HBs Ag-positivity in 3 patients, anti-HCV in 11 patients, alcoholic liver disease in 6 patients, sarcoidosis in 1 patient, and unknown in 2 patients. Thirty of 32 patients with rectal varices had previously received emergency or prophylactic EIS for esophageal varices, and esophageal varices were coexistent in two other patients.

Rectal varices represent portal systemic collaterals that are manifested as discrete dilated submucosal veins and constitute a pathway for portal venous flow between the superior rectal veins of the inferior mesenteric system and the middle inferior rectal veins of the iliac system. Rectal varices have been reported to occur at a high frequency in patients with hepatic abnormalities [8-10]. Massive bleeding from rectal varices occurs rarely, at a frequency ranging from $0.5 \%$ to $3.6 \%$ [11-13]. Rectal varices are an infrequent but potentially serious cause of hematochezia.

Several diagnostic procedures have been performed to evaluate rectal varices, including endoscopy, magnetic resonance (MR) angiography, and endoscopic ultrasonography (EUS). Endoscopy is the principal method for diagnosis of rectal varices, and MR angiography is useful for evaluating
TABle 2: Sites of ectopic varices $(n=43)$.

\begin{tabular}{lc}
\hline Site & Cases $(N)$ \\
\hline Rectal varices & 32 \\
Duodenal varices & 3 \\
Small intestinal varices & 2 \\
Vesical varices & 3 \\
Colonic varices & 2 \\
Stoma varices & 1 \\
\hline Total & 43 \\
\hline
\end{tabular}

the overall portosystemic collateral circulation [14]. EUS has become a useful modality for hemodynamic diagnosis of esophagogastric varices $[15,16]$. The value of EUS [1719] has been reported for the hemodynamic diagnosis of rectal varices, and Dhiman et al. found rectal varices via endoscopy in $43 \%$ and via EUS in $75 \%$, of patients with portal hypertension [19]. Conventional EUS (7.5 or $12 \mathrm{MHz}$ ) reveals rectal varices as rounded, oval, or longitudinal echofree structures in the submucosa and also shows perirectal veins outside the rectal wall [17-19]. EUS was considered superior to endoscopy or MR angiography in making a detailed diagnosis of rectal varices. Sato et al. demonstrated that intramural rectal varices, perirectal collateral veins, and the communicating veins between intramural rectal varices and perirectal collateral veins could be observed clearly via an ultrasonic microprobe [14].

Recently, percutaneous color Doppler ultrasonography (CDUS) has allowed us to detect the flow of blood in fine detail, and it has become widely accepted for the assessment of the hemodynamics of abdominal vascular systems, but few color Doppler findings of gastrointestinal varices have been reported. Komatsuda et al. reported the value of CDUS for the diagnosis of gastric and duodenal varices [20], and Sato et al. have reported the usefulness of CDUS for the hemodynamic evaluation of rectal varices [21].

CDUS cannot be performed successfully without a suitable acoustic window. Impediments such as bowel gas, body habitus, and cirrhosis limit the value of sonography for assessing the portal venous system. In addition, it is difficult to observe the collateral veins far from the probe with color Doppler sonography because of the limitations of Doppler sensitivity. The rectal wall was detected at the posterior area of the vagina in females and the prostate in males by sonography and rectal varices could be observed through the urine-filled bladder via CDUS. Sato et al. suggest that the measurement by CDUS of velocity in rectal varices is useful in diagnosing the grade of rectal varices. CDUS was very useful in screening for rectal varices in portal hypertensive patients [21].

Although EIS and EBL for esophageal varices are wellestablished therapies for esophageal varices, there is no standard treatment for rectal varices. Various medical treatments have been used to control bleeding from rectal varices, but none of these is currently considered to be a standard method. Surgical approaches include portosystemic 
shunting, ligation, and under-running suturing [8]. Some investigators have reported that interventional radiologic techniques such as transjugular intrahepatic portosystemic shunts (TIPSs) were successfully employed for rectal variceal bleeding [22-24]. Wang et al. first reported the usefulness of EIS in treating rectal varices and found it to be effective for controlling bleeding [25]. EBL was introduced as a new method for treating esophageal varices, and it is reportedly easier to perform and safer than EIS. Several cases of successful treatment of rectal varices using EBL have been reported [26-28]. Levine et al. treated rectal varices initially with EIS, and 1 week later, EBL was performed on the remaining rectal varices. These investigators described EBL as a safe and effective therapy for rectal varices. On the other hand, Sato et al. retrospectively evaluated the therapeutic effects and rates of recurrence of rectal varices after EIS or EBL [29], and EIS was successfully performed without complications. The recurrence rate did not differ significantly between the EIS and EBL groups, although recurrence tended to be more frequent with EBL. It is necessary to evaluate the hemodynamics of the rectal varices before EIS to avoid severe complications such as pulmonary embolism, and the sclerosant should be injected slowly under fluoroscopy, taking care to ensure that the agent does not flow into the systemic circulation.

A standard therapy for rectal varices has not been established. More investigations are needed in larger numbers of patients before evidence-based treatment recommendations can be made.

\section{Duodenal Varices}

Three duodenal variceal patients ( 2 males and 1 female) underwent interventional radiology in our ward. The underlying pathology causing portal hypertension included LC in two patients, and IPH in one. In terms of the clinical staging of cirrhosis, all three were graded Child-Pugh class A. The etiologies of LC were anti-HCV-positivity in one patient and alcoholic liver disease in the other. All three patients with duodenal varices had previously received emergency or prophylactic EIS for esophageal varices. The sites of the duodenal varices were the second portion of the duodenum in one case and the distal third portion in two.

The duodenum is a rare site of variceal hemorrhage in patients with portal hypertension but bleeding from duodenal varices is generally massive and life-threatening. It is seen not only in patients with extrahepatic portal hypertension but also in patients with cirrhosis of the liver [30-32]. Duodenal varices are considered to be ectopic varices and account for $1-3 \%$ of all varices in patients with liver cirrhosis [33]. Diagnosis of ruptured duodenal varices and control of bleeding are difficult.

The duodenum can be a site of severe variceal hemorrhage, with mortality as high as $40 \%$ from the initial bleeding $[34,35]$. Although more commonly associated with extrahepatic portal hypertension, duodenal varices may occur in intrahepatic portal hypertension. Cirrhosis of liver is the most common intrahepatic cause of duodenal varices, accounting for $30 \%$ of cases $[31,36]$. Extrahepatic causes vary and include portal vein thrombosis and obstruction of the splenic vein and inferior vena cava $[31,37,38]$.

The most common site of duodenal varices is the duodenal bulb [35], followed by the second portion of the duodenum [39]. Varices in the duodenal bulb, which occur most frequently in the United States and Europe, are caused by extrahepatic portal obstruction. In Japan, duodenal varices are observed more commonly in the second portion of the duodenum $[40,41]$. On the other hand, duodenal varices in the distal third portion are very rare $[42,43]$. Duodenal varices are formed by the developed collateral veins originating from the portal vein trunk or superior mesenteric vein, which empty into the inferior vena cava $[31,34]$.

The bulb and second portion of duodenum can be observed endoscopically. However, location of the bleeding site often is difficult in the duodenum. In our two cases of duodenal varices in the distal third portion, we could not observe the varices by fibergastroscopic examination and we suspected rupture of duodenal varices via computed tomography $(\mathrm{CT})$.

Duodenoscopy and double-balloon enteroscopy were very useful in evaluating the duodenal varices in the distal third portion.

Recently, medical treatments with interventional radiology and endoscopic procedures have been reported for duodenal varices. EBL for bleeding duodenal varices is challenging because of the difficulty in maintaining the field of vision. EBL may be useful for temporary hemostasis $[40,41]$ but rebleeding of duodenal varices is a problem with EBL. Additional treatment is recommended following EBL for duodenal varices. EIS has been reported to be successful in controlling duodenal variceal bleeding $[44,45]$ but there have been reports of cases of rebleeding of duodenal varices after EIS [35, 46]. N-butyl-2-cyanoacrylate (Histoacryl, B.Braun Dexon GmbH Spangenberg, Germany) is a tissue glue monomer that instantly polymerizes and solidifies upon contact with blood. Endoscopic obliterative therapy with Histoacryl seems to be a useful method for bleeding gastric varices $[47,48]$, and it is also suitable for emergency duodenal variceal bleeding $[41,42]$.

Interventional radiologic treatment options for duodenal varices include TIPS, B-RTO, and percutaneous transhepatic obliteration (PTO). B-RTO was successfully performed for two cases of duodenal varices, and PTO for one case, in our ward. Successful treatment of duodenal varices by TIPS [35] and B-RTO [49-51] has been reported. Although TIPS is a relatively safe and effective means of decompressing the portal pressure, it has a certain limitation in patients with severe liver atrophy and complications such as encephalopathy and cerebral embolization. B-RTO can obliterate not only varices but also the afferent and efferent veins and should be considered for treating duodenal varices. Successful treatment of duodenal varices by PTO has been reported $[52,53]$.

\section{Small Intestinal Varices}

Two small intestinal variceal patients (both male, one jejunal varices, and one ileal varices) had undergone interventional 
radiology in our ward. The underlying pathology causing portal hypertension was LC in both. In terms of the clinical staging of cirrhosis, one patient was graded Child-Pugh class $\mathrm{A}$ and the other class B. The etiologies of LC were HBs Agpositivity in one patient and anti-HCV-positivity in the other. The jejunal variceal case had previously undergone gastropylorectomy, and esophageal varices coexisted. The ileal variceal patient had previously received prophylactic EIS for esophageal varices and surgery on the ileocecum to remove a benign colonic tumor.

When repeat upper and lower endoscopies are negative in gastrointestinal bleeding, the small intestine should be investigated. Most bleeding jejunal and ileal varices, generally detected previous to intra-abdominal surgery, are serious because of the difficulty of early diagnosis.

In our two cases, the patients' risk factors included portal hypertension due to liver cirrhosis, and previous surgery. Collaterals formation within adhesions from previous surgery is the usual mechanism for the development of ectopic varices [7]. Adhesions tend to bring the parietal surface of the viscera in contact with the abdominal wall, and portal hypertension results in the formation of varices below the intestinal mucosa.

Location of the bleeding site often is difficult in the intestinal varices. In our two cases, we suspected rupture of intestinal varices via CT. We show jejunal variceal varices, and CT and double-balloon enteroscopy were useful in evaluating the jejunal varices (Figures 1(a) and 1(b)). Lim et al. have reported the usefulness of capsule endoscopy for the diagnosis of bleeding jejunal varices [54].

Several cases of bleeding jejunal [54-59] and ileal varices have been reported [60-68]. A triad of portal hypertension, hematochezia without hematemesis, and previous abdominal surgery characterizes small intestinal varices [69]. Several approaches for the treatment of jejunal varices include surgery [55], portal venous stenting [56, 58, 59], and percutaneous embolization $[54,57]$. Surgical approaches such as segmental resection and ligation generally control bleeding from ileal varices successfully $[64,65,70,71]$. In patients with a poor condition, interventional radiologic treatments, such as insertion of a TIPS for ileal varices, have been performed as a nonsurgical treatment option $[3,66,68]$. Because B-RTO can obliterate not only varices but also the afferent and efferent veins, it is practical for treating ileal varices [72], as described here. In the future, interventional radiologic treatments such as B-RTO may also be applied as therapy for patients in a poor condition. In our cases, B-RTO was successfully performed for jejunal (Figure 2) and ileal varices.

\section{Vesical Varices}

Because our three vesical variceal patients (2 males and 1 female) had a history of EIS for esophageal varices and two had received abdominal surgery, the usual collateral veins from portal hypertension may have been disrupted. Collateral formation within adhesions from previous surgery is the usual mechanism for the development of ectopic varices [7].

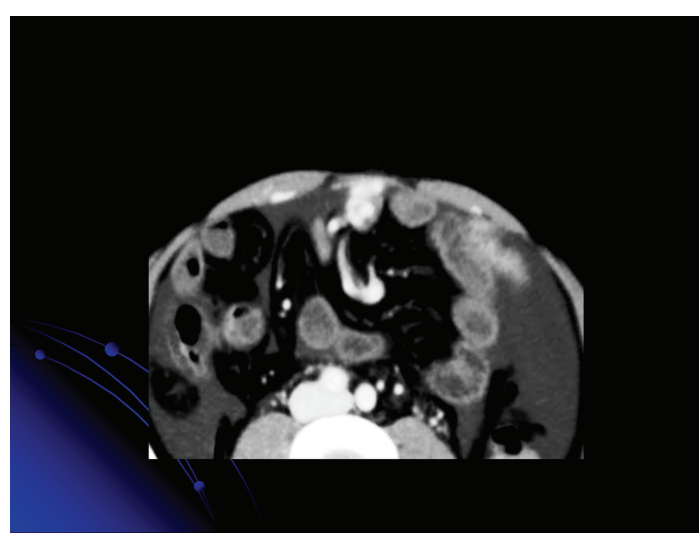

(a)

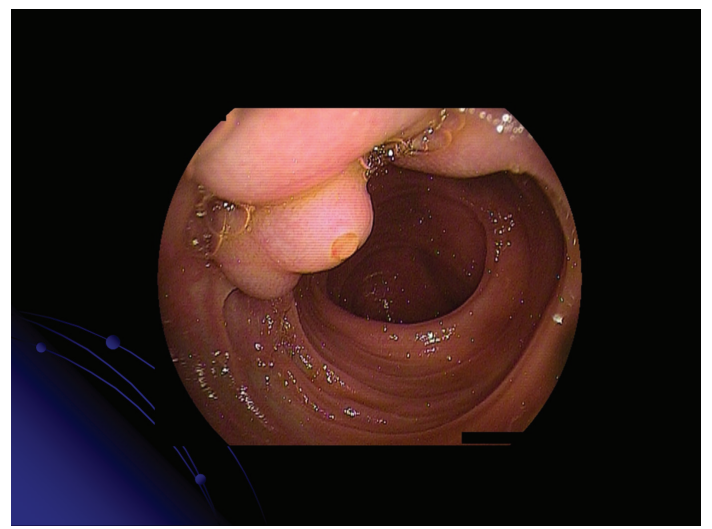

(b)

FIGURE 1: (a) Computed tomography showing the vessel image in the jejunum. (b) Double-balloon enteroscopy revealed jejunal varices with a white plug.

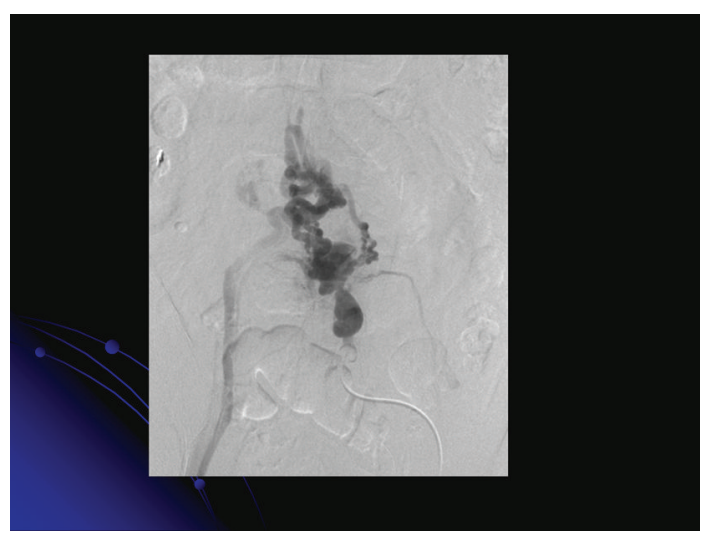

FIGURE 2: Balloon-occluded retrograde transvenous obliteration was performed successfully for jejunal varices.

The underlying pathology causing portal hypertension was LC in one patient, LC-associated HCC in another, and IPH in the third. In terms of the clinical staging of cirrhosis, one patient was graded Child-Pugh class A, one class B, and one class $\mathrm{C}$. The etiologies of $\mathrm{LC}$ were alcoholic in one patient and anti-HCV-positivity in the other. 


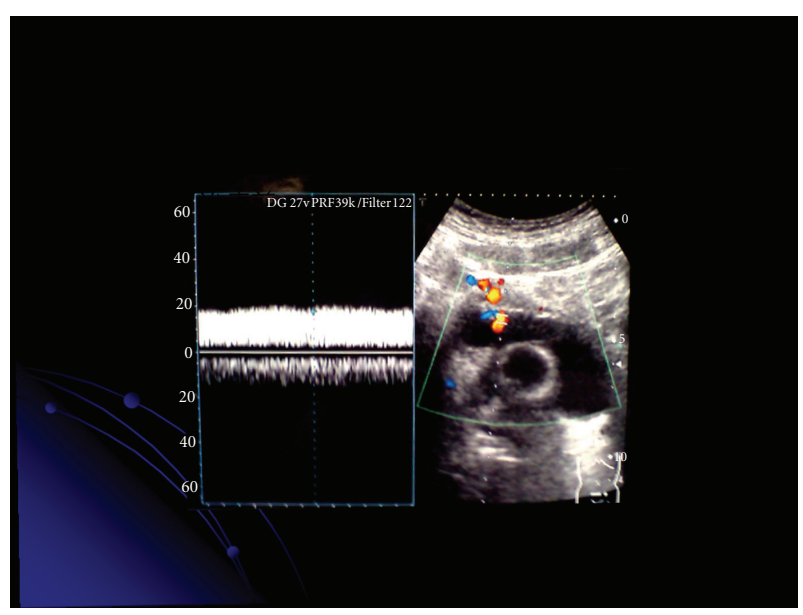

(a)

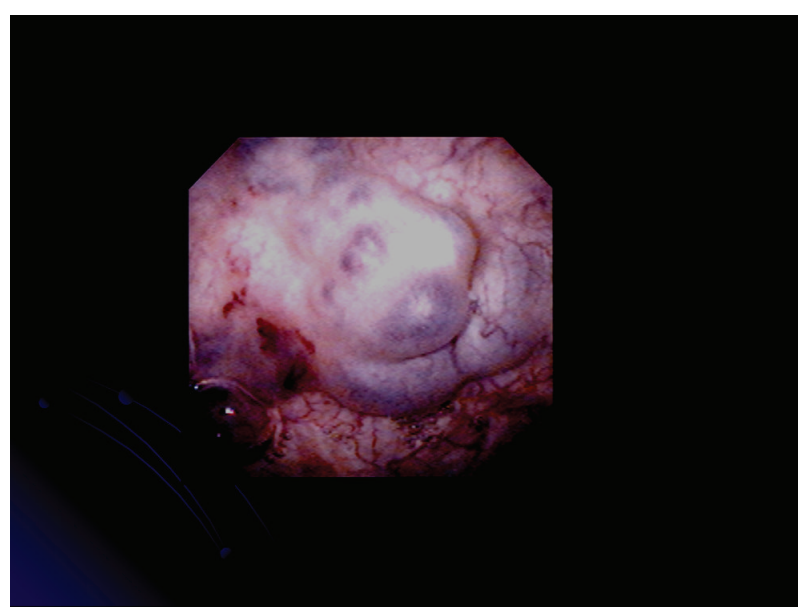

(b)

Figure 3: (a) Color flow images of vesical varices can be delineated clearly in the urine-filled bladder. (b) Cystoscopic examination revealed vesical varices on the anterior wall of the bladder.

Bleeding from vesical varices is rare in patients with portal hypertension $[7,73-76]$ because the bladder wall is an unusual collateral route for the venous splanchnic blood. Previously reported cases of vesical varices had a history of abdominal surgery $[73,74,76,77]$, so that the vesical varices might have appeared after surgery that provided an unusual collateral route resulting from portal hypertension.

CDUS also is very useful for screening for collateral vessels in portal hypertensive patients, in that it can be performed repeatedly. Color flow images of vesical varices can be delineated clearly in the urine-filled bladder. CDUS is very useful for the diagnosis of vesical varices (Figure 3(a)), as is CT. Cystoscopic examination revealed vesical varices on the anterior wall of the bladder in our cases (Figure 3(b)).

No definitive treatment has been established for bleeding vesical varices. We used PTP to reveal the detailed hemodynamics of the collateral circulation in vesical variceal patients, including the afferent and efferent veins, and these patients were successfully treated with PTO [77].

\section{Colonic Varices}

Two colonic variceal patients (both female, one descending colonic varices and one transverse colonic varices) underwent interventional radiology (PTO) and EIS in our ward. The underlying pathology causing portal hypertension was LC in both. In terms of the clinical staging of cirrhosis, both were graded Child-Pugh class A. Both were anti-HCVpositive and had a history of EIS for esophageal varices, and one had received abdominal surgery.

The most common sites of colorectal varices are the rectum and cecum [78]. Colonic varices can be associated with several conditions, such as portal hypertension, portal venous obstruction, postsurgical changes, and idiopathic factors $[3,79-84]$.

Colonoscopy is the principal method for the diagnosis of colonic varices, and MR angiography is useful for evaluating the overall portosystemic collateral circulation. CT has been reported rarely but has shown a colonic wall which is thickened with a scalloped appearance [85]. In our cases, we suspected colonic varices via CT [86].

Several therapies, including PTO, colonic resection, portacaval shunt construction, endoscopic procedures, TIPS, variceal embolization, and B-RTO, have been reported [3, $79-84,86-90]$. The treatment of colonic varices is not well defined.

\section{Stomal Varices}

The (male) stomal variceal patient in our ward had undergone interventional radiology (TIPS). The underlying pathology causing portal hypertension was LC (Child-Pugh class B), and he was anti-HCV-positive. This case had previously received Miles' operation for rectal cancer, and EIS had been performed for esophageal varices.

Stomal varices can occur in patients with stoma in the presence of portal hypertension and remain difficult to diagnose and manage. The overall morbidity of the stomal varices is much higher given the propensity for recurrence and massive bleeding, requiring multiple blood transfusions [91, 92].

The mechanism of stomal variceal hemorrhage is related to variceal erosion or local trauma. Several management strategies have been described for stomal variceal hemorrhage, including local therapy, EIS, TIPS, B-RTO, and surgery. Although local therapies are effective for the initial control of bleeding, these may be not effective in preventing recurrent bleeding [93]. EIS is effective for controlling stomal variceal bleeding [94], and portosystemic surgery is effective for prevention of recurrent bleeding but also is associated with significant morbidity and mortality [95]. PTO has been used safely for acute stomal variceal bleeding [92, 96, 97]; however, recurrent bleeding is frequent. TIPS is an effective therapy for bleeding stomal varices [98-100] but may result in a higher mortality of patients with severe decompensated liver function because of encephalopathy, rather than the stomal variceal bleeding itself [96]. Recently, Minami et al. have reported that B-RTO was useful for recurrent hemorrhage from stomal varices [101]. 


\section{Conclusions}

It is difficult to determine the best treatment strategy for ectopic varices because of inaccessibility, initial difficulty in diagnosis, and subsequent difficulty in treatment. Hemorrhage from ectopic varices should be kept in mind in patients with portal hypertension presenting with lower gastrointestinal bleeding.

\section{Acknowledgment}

The authors thank Dr. Katsu Yamazaki who contributed clinical data to this paper.

\section{References}

[1] G. Walsh and M. P. Williams, "Case report: giant pararectal varices-computed tomographic appearances," The British Journal of Radiology, vol. 68, no. 806, pp. 203-204, 1995.

[2] M. Kinkhabwala, A. Mousavi, S. Iyer, and R. Adamsons, "Bleeding ileal varicosity demonstrated by transhepatic portography," The American Journal of Roentgenology, vol. 129, no. 3, pp. 514-516, 1977.

[3] I. D. Norton, J. C. Andrews, and P. S. Kamath, "Management of ectopic varices," Hepatology, vol. 28, no. 4 I, pp. 1154 $1158,1998$.

[4] The Veterans Affairs Cooperative Variceal Sclerotherapy Group, "Prophylactic sclerotherapy for esophageal varices in men with alcoholic liver disease," The New England Journal of Medicine, vol. 324, pp. 1779-1784, 1991.

[5] J. S. Goff, R. M. Reveille, and G. V. Stiegmann, "Endoscopic sclerotherapy versus endoscopic variceal ligation: esophageal symptoms, complications and motility," The American Journal of Gastroenterology, vol. 83, no. 11, pp. 1240-1244, 1988.

[6] H. Kanagawa, S. Mima, H. Kouyama, K. Gotoh, T. Uchida, and K. Okuda, "Treatment of gastric fundal varices by balloon-occluded retrograde transvenous obliteration," Journal of Gastroenterology and Hepatology, vol. 11, no. 1, pp. 51-58, 1996.

[7] D. Lebrec and J. P. Benhamou, "Ectopic varices in portal hypertension," Clinics in Gastroenterology, vol. 14, no. 1, pp. 105-121, 1985.

[8] S. W. Hosking, A. G. Johnson, H. L. Smart, and D. R. Triger, "Anorectal varices, haemorrhoids and portal hypertension," The Lancet, vol. 1, no. 8634, pp. 349-352, 1989.

[9] T. F. Wang, F. Y. Lee, Y. T. Tsai et al., "Relationship of portal pressure, anorectal varices and hemorrhoids in cirrhotic patients," Journal of Hepatology, vol. 15, no. 1-2, pp. 170-173, 1992.

[10] Y. K. Chawla and J. B. Dilawari, "Anorectal varices-their frequency in cirrhotic and non-cirrhotic portal hypertension," Gut, vol. 32, no. 3, pp. 309-311, 1991.

[11] T. T. McCormack, H. R. Bailey, J. M. Simms, and A. G. Johnson, "Rectal varices are not piles," The British Journal of Surgery, vol. 71, no. 2, p. 163, 1984.

[12] K. Johansen, J. Bardin, and M. J. Orloff, "Massive bleeding from hemorrhoidal varices in portal hypertension," Journal of the American Medical Association, vol. 244, no. 18, pp. 20842085, 1980.

[13] S. E. Wilson, R. T. Stone, J. P. Christie, and E. Passaro, "Massive lower gastrointestinal bleeding from intestinal varices," Archives of Surgery, vol. 114, no. 10, pp. 1158-1161, 1979.
[14] T. Sato, K. Yamazaki, J. Toyota, Y. Karino, T. Ohmura, and T. Suga, "The value of the ultrasonic microprobe in the detection and treatment of rectal varices: a case report," Hepatology Research, vol. 27, no. 2, pp. 158-162, 2003.

[15] G. C. Caletti, L. Bolondi, E. Zani et al., "Detection of portal hypertension and esophageal varices by means of endoscopic ultrasonography," Scandinavian Journal of Gastroenterology, vol. 123, pp. 74-77, 1986.

[16] G. C. Caletti, E. Brocchi, A. Ferrari, S. Fiorino, and L. Barbara, "Value of endoscopic ultrasonography in the management of portal hypertension," Endoscopy, vol. 24, no. 1, pp. 342-346, 1992.

[17] R. K. Dhiman, G. Choudhuri, V. A. Saraswat et al., "Endoscopic ultrasonographic evaluation of the rectum in cirrhotic portal hypertension," Gastrointestinal Endoscopy, vol. 39, no. 5, pp. 635-640, 1993.

[18] S. K. Yachha, R. K. Dhiman, R. Gupta, and U. C. Ghoshal, "Endosonographic evaluation of the rectum in children with extrahepatic portal venous obstruction," Journal of Pediatric Gastroenterology and Nutrition, vol. 23, no. 4, pp. 438-441, 1996.

[19] R. K. Dhiman, V. A. Saraswat, G. Choudhuri, B. C. Sharma, R. Pandey, and S. R. Naik, "Endosonographic, endoscopic and histologic evaluation of alterations in the rectal venous system in patients with portal hypertension," Gastrointestinal Endoscopy, vol. 49, no. 2, pp. 218-227, 1999.

[20] T. Komatsuda, H. Ishida, K. Konno et al., "Color Doppler findings of gastrointestinal varices," Abdominal Imaging, vol. 23, no. 1, pp. 45-50, 1998.

[21] T. Sato, K. Yamazaki, J. Toyota, Y. Karino, T. Ohmura, and J. Akaike, "Diagnosis of rectal varices via color Doppler ultrasonography," The American Journal of Gastroenterology, vol. 102, no. 10, pp. 2253-2258, 2007.

[22] J. A. Katz, R. A. Rubin, C. Cope, G. Holland, and C. A. Brass, "Recurrent bleeding from anorectal varices: successful treatment with a transjugular intrahepatic portosystemic shunt," The American Journal of Gastroenterology, vol. 88, no. 7, pp. 1104-1107, 1993.

[23] D. Shibata, D. P. Brophy, F. D. Gordon, H. T. Anastopoulos, S. M. Sentovich, and R. Bleday, "Transjugular intrahepatic portosystemic shunt for treatment of bleeding ectopic varices with portal hypertension," Diseases of the Colon and Rectum, vol. 42, no. 12, pp. 1581-1585, 1999.

[24] A. C. Fantin, G. Zala, B. Risti, J. F. Debatin, W. Schöpke, and C. Meyenberger, "Bleeding anorectal varices: successful treatment with transjugular intrahepatic portosystemic shunting (TIPS)," Gut, vol. 38, no. 6, pp. 932-935, 1996.

[25] M. Wang, G. Desigan, and D. Dunn, "Endoscopic sclerotherapy for bleeding rectal varices: a case report," The American Journal of Gastroenterology, vol. 80, no. 10, pp. 779-780, 1985.

[26] J. Levine, A. Tahiri, and B. Banerjee, "Endoscopic ligation of bleeding rectal varices," Gastrointestinal Endoscopy, vol. 39, no. 2, pp. 188-190, 1993.

[27] B. Firoozi, Z. Gamagaris, E. H. Weinshel, and E. J. Bini, "Endoscopic band ligation of bleeding rectal varices," Digestive Diseases and Sciences, vol. 47, no. 7, pp. 1502-1505, 2002.

[28] T. Sato, K. Yamazaki, J. Toyota, Y. Karino, T. Ohmura, and T. Suga, "Two cases of rectal varices treated by endoscopic variceal ligation," Digestive Endoscopy, vol. 11, no. 1, pp. 6669, 1999.

[29] T. Sato, K. Yamazaki, J. Toyota, Y. Karino, T. Ohmura, and T. Suga, "The value of the endoscopic therapies in the treatment 
of rectal varices: a retrospective comparison between injection sclerotherapy and band ligation," Hepatology Research, vol. 34, no. 4, pp. 250-255, 2006.

[30] Y. Itzchak and M. G. Glickman, "Duodenal varices in extrahepatic portal obstruction," Radiology, vol. 124, no. 3, pp. 619-624, 1977.

[31] R. Amin, R. Alexis, and J. Korzis, "Fatal ruptured duodenal varix: a case report and review of literature," The American Journal of Gastroenterology, vol. 80, no. 1, pp. 13-18, 1985.

[32] T. Tanaka, K. Kato, T. Taniguchi, D. Takagi, N. Takeyama, and Y. Kitazawa, "A case of ruptured duodenal varices and review of the literature," Japanese Journal of Surgery, vol. 18, no. 5, pp. 595-600, 1988.

[33] N. D’Imperio, A. Piemontese, D. Baroncini et al., "Evaluation of undiluted N-butyl-2-cyanoacrylate in the endoscopic treatment of upper gastrointestinal tract varices," Endoscopy, vol. 28, no. 2, pp. 239-243, 1996.

[34] F. Khouqeer, C. Morrow, and P. Jordan, "Duodenal varices as a cause of massive upper gastrointestinal bleeding," Surgery, vol. 102, no. 3, pp. 548-552, 1987.

[35] S. S. Jonnalagadda, S. Quiason, and O. J. Smith, "Successful therapy of bleeding duodenal varices by TIPS after failure of sclerotherapy," The American Journal of Gastroenterology, vol. 93, no. 2, pp. 272-274, 1998.

[36] M. Hashizume, K. Tanoue, M. Ohta et al., "Vascular anatomy of duodenal varices: angiographic and histopathological assessments," The American Journal of Gastroenterology, vol. 88, no. 11, pp. 1942-1945, 1993.

[37] K. M. Brown, M. M. Kaplan, and M. Donowitz, "Extrahepatic portal venous thrombosis: frequent recognition of associated diseases," Journal of Clinical Gastroenterology, vol. 7, no. 2, pp. 153-159, 1985.

[38] J. H. Grendell and R. K. Ockner, "Mesenteric venous thrombosis," Gastroenterology, vol. 82, no. 2, pp. 358-372, 1982.

[39] C. S. Wang, L. B. Jeng, and M. F. Chen, "Duodenal variceal bleeding-successfully treated by mesocaval shunt after failure of sclerotherapy," Hepato-Gastroenterology, vol. 42, no. 1, pp. 59-61, 1995.

[40] M. Shiraishi, S. Hiroyasu, T. Higa, S. Oshiro, and Y. Muto, "Successful management of ruptured duodenal varices by means of endoscopic variceal ligation: report of a case," Gastrointestinal Endoscopy, vol. 49, no. 2, pp. 255-257, 1999.

[41] Y. Yoshida, Y. Imai, M. Nishikawa et al., "Successful endoscopic injection sclerotherapy with N-butyl-2-cyanoacrylate following the recurrence of bleeding soon after endoscopic ligation for ruptured duodenal varices," The American Journal of Gastroenterology, vol. 92, no. 7, pp. 1227-1229, 1997.

[42] K. Ota, Z. Shirai, T. Masuzaki et al., "Endoscopic injection sclerotherapy with n-butyl-2-cyanoacrylate for ruptured duodenal varices," Journal of Gastroenterology, vol. 33, no. 4, pp. 550-555, 1998.

[43] H. Selçuk, F. Boyvat, S. Eren et al., "Duodenal varices as an unusual cause of gastrointestinal bleeding due to portal hypertension: a case report," Turkish Journal of Gastroenterology, vol. 15, no. 2, pp. 104-107, 2004.

[44] P. Gertsch and L. H. Blumgart, "Cure of a bleeding duodenal varix by sclerotherapy," The British Journal of Surgery, vol. 75, no. 7, p. $717,1988$.

[45] A. W. Barbish and M. N. Ehrinpreis, "Successful endoscopic injection sclerotherapy of a bleeding duodenal varix," The American Journal of Gastroenterology, vol. 88, no. 1, pp. 9092, 1993.
[46] M. Hashiguchi, H. Tsuji, J. Shimono, K. Azuma, and M. Fujishima, "Ruptured duodenal varices: an autopsy case report," Hepato-Gastroenterology, vol. 46, no. 27, pp. 17511754, 1999.

[47] K. Ogawa, S. Ishikawa, Y. Naritaka et al., "Clinical evaluation of endoscopic injection sclerotherapy using n-butyl2-cyanoacrylate for gastric variceal bleeding," Journal of Gastroenterology and Hepatology, vol. 14, no. 3, pp. 245-250, 1999.

[48] Y. H. Huang, H. Z. Yeh, G. H. Chen et al., "Endoscopic treatment of bleeding gastric varices by N-butyl-2-cyanoacrylate (Histoacryl) injection: long-term efficacy and safety," Gastrointestinal Endoscopy, vol. 52, no. 2, pp. 160-167, 2000.

[49] M. Ohta, K. Yasumori, M. Saku, H. Saitsu, T. Muranaka, and K. Yoshida, "Successful treatment of bleeding duodenal varices by balloon-occluded retrograde transvenous obliteration: a transjugular venous approach," Surgery, vol. 126, no. 3, pp. 581-583, 1999.

[50] Y. Akazawa, I. Murata, T. Yamao et al., "Successful management of bleeding duodenal varices by endoscopic variceal ligation and balloon-occluded retrograde transvenous obliteration," Gastrointestinal Endoscopy, vol. 58, no. 5, pp. 794797, 2003.

[51] T. Sonomura, K. Horihata, K. Yamahara et al., "Ruptured duodenal varices successfully treated with balloon-occluded retrograde transvenous obliteration: usefulness of microcatheters," The American Journal of Roentgenology, vol. 181, no. 3, pp. 725-727, 2003.

[52] Y. Menu, B. Gayet, and H. Nahum, "Bleeding duodenal varices: diagnosis and treatment by percutaneous portography and transcatheter embolization," Gastrointestinal Radiology, vol. 12, no. 1, pp. 111-113, 1987.

[53] T. Sato, K. Yamazaki, J. Toyota et al., "Efficacy of color Doppler ultrasonography for the diagnosis of duodenal varices successfully treated with percutaneous transhepatic obliteration," Journal of Medical Ultrasonics, vol. 34, no. 1, pp. 59-63, 2007.

[54] L. G. Lim, Y. M. Lee, L. Tan, S. Chang, and S. G. Lim, "Percutaneous paraumbilical embolization as an unconventional and successful treatment for bleeding jejunal varices," World Journal of Gastroenterology, vol. 15, no. 30, pp. 3823-3826, 2009.

[55] N. Yuki, M. Kubo, Y. Noro et al., "Jejunal varices as a cause of massive gastrointestinal bleeding," The American Journal of Gastroenterology, vol. 87, no. 4, pp. 514-517, 1992.

[56] M. Sakai, A. Nakao, T. Kaneko et al., "Transhepatic portal venous angioplasty with stenting for bleeding jejunal varices," Hepato-Gastroenterology, vol. 52, no. 63, pp. 749752, 2005.

[57] A. Sasamoto, J. Kamiya, Y. Nimura, and M. Nagino, "Successful embolization therapy for bleeding from jejunal varices after choledochojejunostomy: report of a case," Surgery Today, vol. 40, no. 8, pp. 788-791, 2010.

[58] K. Hiraoka, S. Kondo, Y. Ambo et al., "Portal venous dilatation and stenting for bleeding jejunal varices: report of two cases," Surgery Today, vol. 31, no. 11, pp. 1008-1011, 2001.

[59] S. Ota, S. Suzuki, H. Mitsuoka et al., "Effect of a portal venous stent for gastrointestinal hemorrhage from jejunal varices caused by portal hypertension after pancreatoduodenectomy," Journal of Hepato-Biliary-Pancreatic Surgery, vol. 12, no. 1, pp. 88-92, 2005.

[60] K. R. Falchuk, M. R. Aiello, C. Trey, and P. Costello, "Recurrent gastrointestinal bleeding from ileal varices associated with intraabdominal adhesions: case report and review of 
the literature," The American Journal of Gastroenterology, vol. 77, no. 11, pp. 859-860, 1982.

[61] H. F. Arst and J. D. Reynolds, "Acute ileal variceal hemorrhage secondary to esophageal sclerotherapy," Journal of Clinical Gastroenterology, vol. 8, no. 5, pp. 603-604, 1986.

[62] J. H. Hojhus and S. A. Pedersen, "Cirrhosis and bleeding ileal varices without previous intraabdominal surgery. A case report," Acta Chirurgica Scandinavica, vol. 152, pp. 479-480, 1986.

[63] P. Lewis, B. F. Warren, and D. C. Bartolo, "Massive gastrointestinal haemorrhage due to ileal varices," The British Journal of Surgery, vol. 77, no. 11, pp. 1277-1278, 1990.

[64] T. Ohtani, E. Kajiwara, N. Suzuki et al., "Ileal varices associated with recurrent bleeding in a patient with liver cirrhosis," Journal of Gastroenterology, vol. 34, no. 2, pp. 264268, 1999.

[65] K. Kobayashi, J. Yamaguchi, A. Mizoe et al., "Successful treatment of bleeding due to ileal varices in a patient with hepatocellular carcinoma," European Journal of Gastroenterology and Hepatology, vol. 13, no. 1, pp. 63-66, 2001.

[66] E. Guth, M. D. Katz, S. E. Hanks, G. P. Teitelbaum, P. Ralls, and J. Korula, "Recurrent bleeding from ileal varices treated by transjugular intrahepatic portosystemic shunt: value of Doppler ultrasonography in diagnosis and followup," Journal of Ultrasound in Medicine, vol. 15, no. 1, pp. 6769, 1996.

[67] R. V. Varanasi, A. S. Fleischer, P. E. Darwin, C. E. King, and O. Haluszka, "Colonoscopic sclerotherapy of ileal varices," Gastrointestinal Endoscopy, vol. 52, pp. 109-111, 2000.

[68] R. Lopez-Benitez, P. Seidensticker, G. M. Richter, U. Stampfl, and P. Hallscheidt, "Case report: massive lower intestinal bleeding from ileal varices: treatment with transjugular intrahepatic portosystemic shunt (TIPSS)," Der Radiologe, vol. 47, pp. 407-410, 2007 (German).

[69] M. S. Cappell and J. B. Price, "Characterization of the syndrome of small and large intestinal variceal bleeding," Digestive Diseases and Sciences, vol. 32, no. 4, pp. 422-427, 1987.

[70] J. Ueda, H. Yoshida, Y. Mamada et al., "Successful emergency enterectomy for bleeding ileal varices in a patient with liver cirrhosis," Journal of Nippon Medical School, vol. 73, pp. 221225, 2006 (Japanese).

[71] M. Mashimo, J. Hara, A. Nitta et al., "A case of ruptured ileal varices associated with alcoholic liver cirrhosis," Nippon Shokakibyo Gakkai Zasshi, vol. 104, pp. 561-567, 2007 (Japanese).

[72] I. Haruta, Y. Isobe, E. Ueno et al., "Balloon-occluded retrograde transvenous obliteration (BRTO), a promising nonsurgical therapy for ectopic varices," The American Journal of Gastroenterology, vol. 91, no. 12, pp. 2594-2597, 1996.

[73] K. Sano, T. Shuin, S. Takebayashi et al., "A case of vesical varices as a complication of portal hypertension and manifested gross hematuria," Journal of Urology, vol. 141, no. 2, pp. 369-371, 1989.

[74] P. M. Lugagne, D. Castaing, P. Conort, M. Guerrieri, O. Bousquet, and C. Chatelain, "Portal hypertension: a rare cause of hematuria," Progres en Urologie, vol. 2, no. 2, pp. 294-298, 1992.

[75] G. Loganathan, N. K. Shyamkumar, G. Kurian et al., "Vesical varix in cirrhosis of liver," The Indian Journal of Gastroenterology, vol. 19, no. 4, pp. 193-194, 2000.

[76] Y. Gaspar, O. Detry, and J. De Leval, "Vesical varices in a patient with portal hypertension," The New England Journal of Medicine, vol. 345, no. 20, pp. 1503-1504, 2001.
[77] T. Sato, "Transabdominal color Doppler ultrasonography for the diagnosis of small intestinal and vesical varices in a patient successfully treated with percutaneous transhepatic obliteration," Clinical Journal of Gastroenterology, vol. 3, pp. 214-218, 2010.

[78] A. N. Hamlyn, J. S. Morris, M. R. Lunzer, H. Puritz, and R. Dick, "Portal hypertension with varices in unusual sites," The Lancet, vol. 2, no. 7896, pp. 1531-1534, 1974.

[79] E. M. Izsak and J. M. Finlay, "Colonic varices. Three case reports and review of the literature," The American Journal of Gastroenterology, vol. 73, no. 2, pp. 131-136, 1980.

[80] Y. M. Miao, S. M. Catnach, I. G. Barrison, A. O’Reilly, and A. R. Divers, "Colonic variceal bleeding in a patient with mesenteric venous obstruction due to an ileal carcinoid tumor," European Journal of Gastroenterology and Hepatology, vol. 8, pp. 1133-1135, 1996.

[81] S. D. Klein, J. C. Hellinger, M. L. Silverstein, and Q. Cai, "Isolated cecal varices as the source of massive lower GI bleeding in a patient with cirrhosis," The American Journal of Gastroenterology, vol. 98, no. 1, pp. 220-221, 2003.

[82] R. J. Detry, A. Kartheuser, R. Moisse et al., "Idiopathic nonfamilial rectal and colonic varices requiring sigmoidorectal resection and coloanal anastomosis," European Journal of Gastroenterology and Hepatology, vol. 8, no. 10, pp. 10231026, 1996.

[83] R. Shrestha, J. C. Dunkelberg, and J. W. Schaefer, "Idiopathic colonic varices: an unusual cause of massive lower gastrointestinal hemorrhage," The American Journal of Gastroenterology, vol. 90, no. 3, pp. 496-497, 1995.

[84] J. P. Iredale, P. Ridings, F. P. McGinn, and M. J. Arthur, "Familial and idiopathic colonic varices: an unusual cause of lower gastrointestinal haemorrhage," Gut, vol. 33, no. 9, pp. 1285-1288, 1992.

[85] T. R. Smith, "CT demonstration of ascending colon varices," Clinical Imaging, vol. 18, no. 1, pp. 4-6, 1994.

[86] T. Sato, K. Yamazaki, J. Akaike et al., "Transverse colonic varices successfully treated with endoscopic procedure," Clinical Journal of Gastroenterology, vol. 1, pp. 52-55, 2008.

[87] H. P. Allgaier, A. Ochs, K. Haag et al., "Recurrent bleeding from colonic varices in portal hypertension. The successful prevention of recurrence by the implantation of a transjugular intrahepatic stent-shunt (TIPS)," Deutsche Medizinische Wochenschrift, vol. 120, no. 51-52, pp. 1773-1776, 1995.

[88] P. Chevallier, J. P. Motamedi, N. Demuth, F. X. Caroli-Bosc, F. Oddo, and B. Padovani, "Ascending colonic variceal bleeding: utility of phase-contrast MR portography in diagnosis and follow-up after treatment with TIPS and variceal embolization," European Radiology, vol. 10, no. 8, pp. 1280-1283, 2000.

[89] S. P. Misra and M. Dwivedi, "Ligation of a bleeding colonic varix using an upper gastrointestinal endoscope," Endoscopy, vol. 38, no. 6, p. 657, 2006.

[90] A. Anan, M. Irie, H. Watanabe et al., "Colonic varices treated by balloon-occluded retrograde transvenous obliteration in a cirrhotic patient with encephalopathy: a case report," Gastrointestinal Endoscopy, vol. 63, no. 6, pp. 880-884, 2006.

[91] N. B. Ackerman, G. M. Graeber, and J. Fey, "Enterostomal varices secondary to portal hypertension: progression of disease in conservatively managed cases," Archives of Surgery, vol. 115, no. 12, pp. 1454-1455, 1980.

[92] R. N. Samaraweera, L. Feldman, W. C. Widrich et al., "Stomal varices: percutaneous transhepatic embolization," Radiology, vol. 170, no. 3, pp. 779-782, 1989. 
[93] P. L. Roberts, F. M. Martin, D. J. Schoetz Jr., J. J. Murray, J. A. Coller, and M. C. Veidenheimer, "Bleeding stomal varices. The role of local treatment," Diseases of the Colon and Rectum, vol. 33, no. 7, pp. 547-549, 1990.

[94] H. C. Wolfsen, R. A. Kozarek, J. E. Bredfeldt, L. F. Fenster, and L. L. Brubacher, "The role of endoscopic injection sclerotherapy in the management of bleeding peristomal varices," Gastrointestinal Endoscopy, vol. 36, no. 5, pp. 472-474, 1990.

[95] W. D. Warren, W. J. Millikan Jr., J. M. Henderson et al., “Ten years portal hypertensive surgery at Emory: results and new perspectives," Annals of Surgery, vol. 195, pp. 530-542, 1982.

[96] K. Kishimoto, A. Hara, T. Arita et al., "Stomal varices: treatment by percutaneous transhepatic coil embolization," CardioVascular and Interventional Radiology, vol. 22, pp. 523525, 1999.

[97] S. G. Naidu, E. P. Castle, J. S. Kriegshauser, and E. A. Huettl, "Direct percutaneous embolization of bleeding stomal varices," CardioVascular and Interventional Radiology, vol. 33, pp. 201-204, 2010.

[98] G. D. Weinberg, T. A. Matalon, M. C. Brunner, S. K. Patel, and R. Sandler, "Bleeding stomal varices: treatment with a transjugular intrahepatic portosystemic shunt in two pediatric patients," Journal of Vascular and Interventional Radiology, vol. 6, no. 2, pp. 233-236, 1995.

[99] C. S. Morris and K. E. Najarian, "Transjugular intrahepatic portosystemic shunt for bleeding stomal varices associated with chronic portal vein occlusion: long-term angiographic, hemodynamic, and clinical follow-up," The American Journal of Gastroenterology, vol. 95, no. 10, pp. 2966-2968, 2000.

[100] R. K. Ryu, A. A. Nemcek, H. B. Chrisman et al., "Treatment of stomal variceal hemorrhage with TIPS: case report and review of the literature," CardioVascular and Interventional Radiology, vol. 23, pp. 301-303, 2000.

[101] S. Minami, K. Okada, M. Matsuo, Y. Kamohara, I. Sakamoto, and T. Kanematsu, "Treatment of bleeding stomal varices by balloon-occluded retrograde transvenous obliteration," Journal of Gastroenterology, vol. 42, pp. 91-95, 2007. 


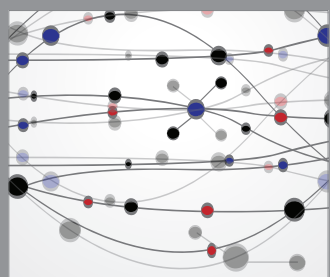

The Scientific World Journal
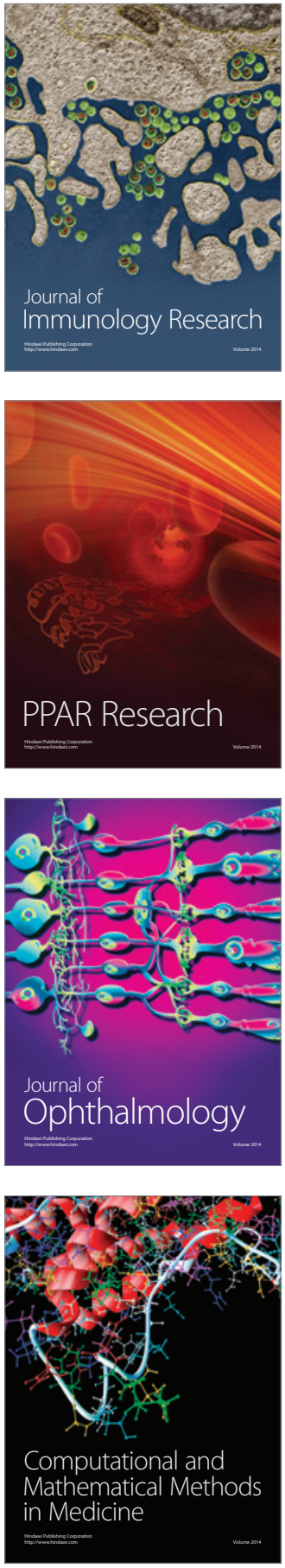

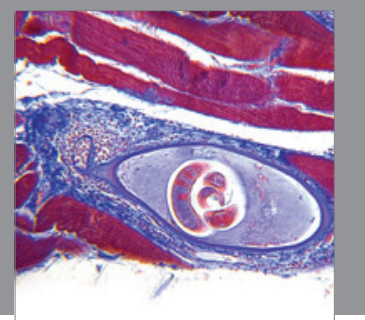

Gastroenterology

Research and Practice
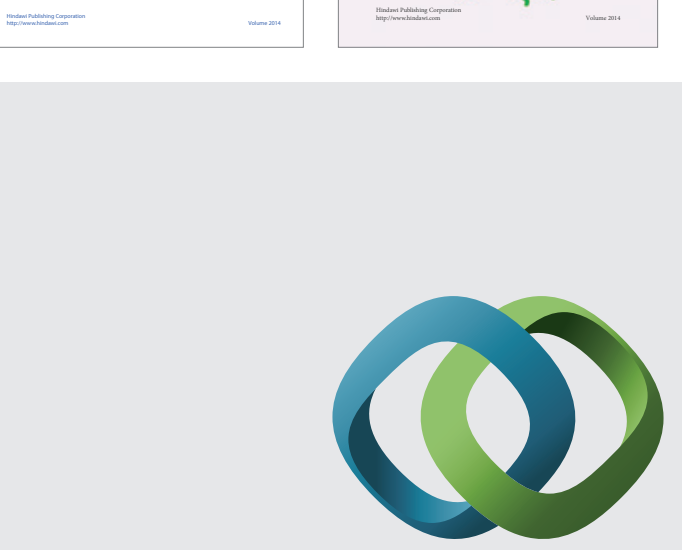

\section{Hindawi}

Submit your manuscripts at

http://www.hindawi.com
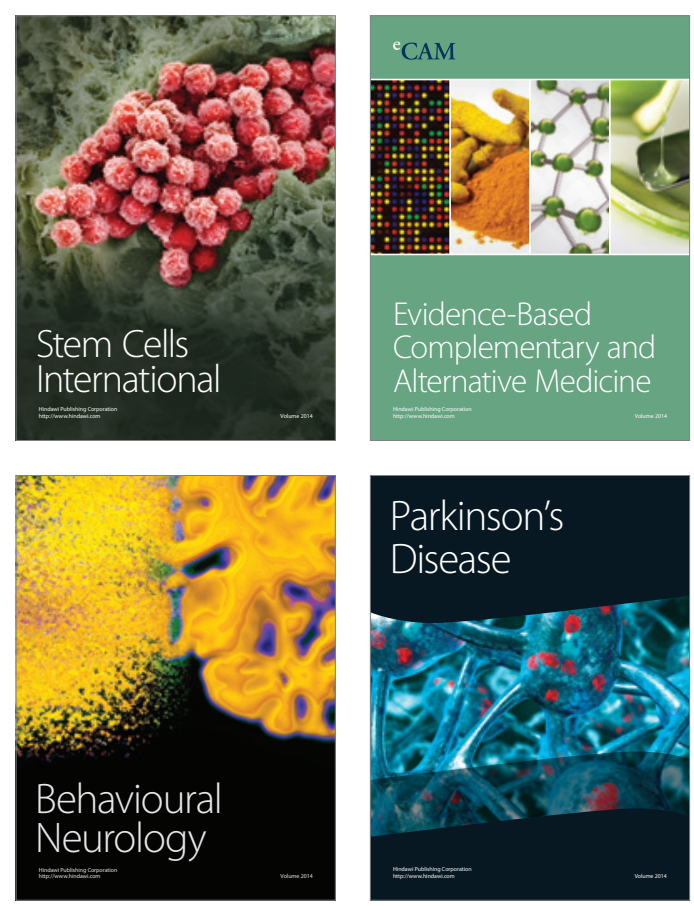

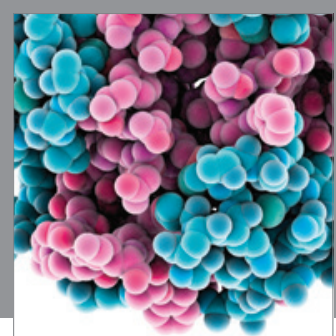

Journal of
Diabetes Research

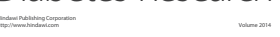

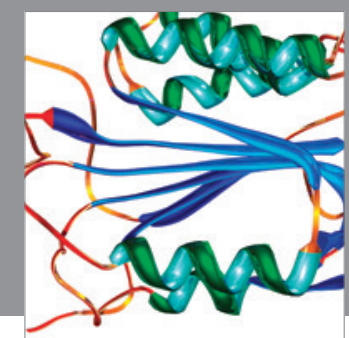

Disease Markers
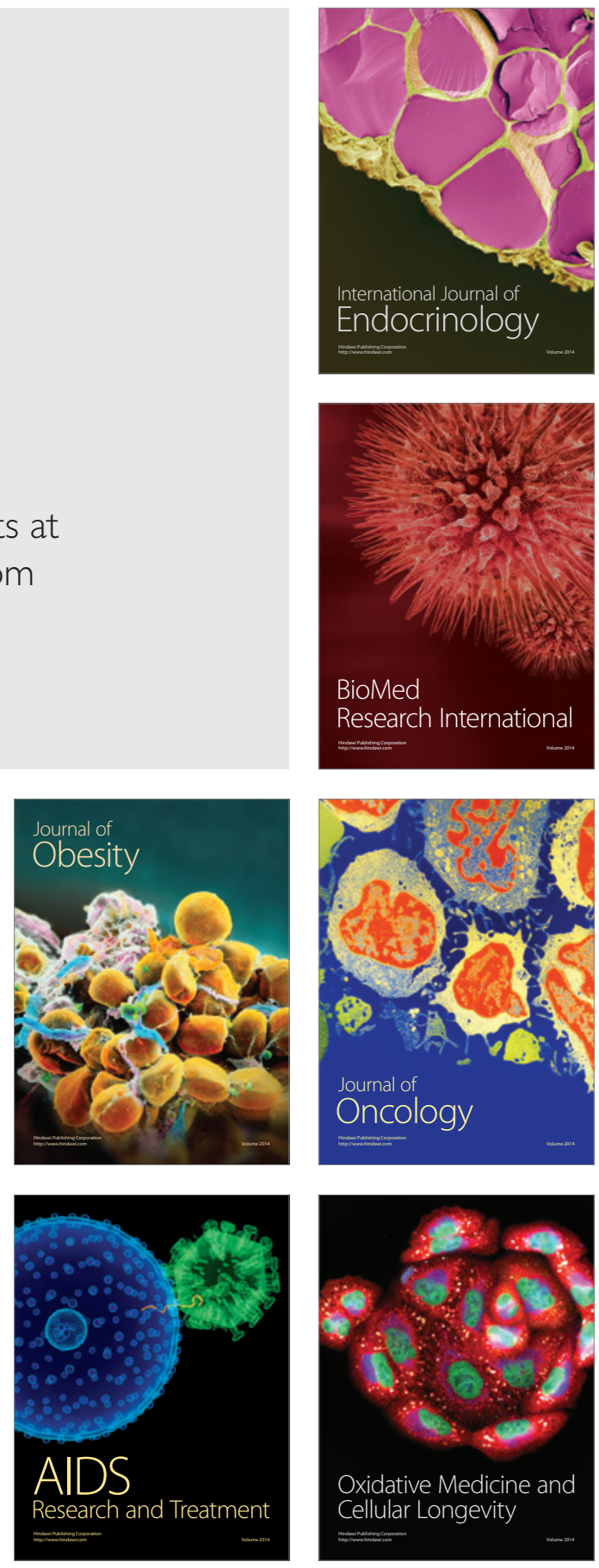